\title{
SOFTWARE LIVRE NA EDUCAÇÃO PARA ALÉM DA INCLUSÃO DIGITAL E SOCIAL: LETRAMENTOS MÚLTIPLOS DE PROFESSORES E ALUNOS
}

Jaiza Helena Moisés Fernandes

\begin{abstract}
RESUMO: O software livre (SL) está presente em muitos espaços do convívio social, vencendo barreiras econômicas, políticas, culturais e filosóficas da exclusão. O presente artigo tem como objetivo destacar a importância da inserção do software livre no contexto de sala de aula, a partir de um relato de experiência em turmas de $2^{\circ}$ ano do Ensino Fundamental no município de Fortaleza. O uso potencial do computador e do software livre Linux Educacional 3.0 e seus aplicativos contribuiu de forma significativa para a mudança na qualidade da educação, possibilitando a inclusão digital e social e letramentos múltiplos de professores e alunos. Os resultados e conclusões deste artigo motivam a pesquisadora a continuar investigando e produzindo outros materiais pedagógicos digitais e tutoriais dos aplicativos do software livre. Dessa forma, busca-se contribuir para a divulgação das possibilidades educativas desse sistema operacional e, por conseguinte, para a formação continuada dos professores.
\end{abstract}

PALAVRAS-CHAVE: Software livre. Linux Educacional. Inclusão escolar. Aprendizagens significativas. Letramentos.

\begin{abstract}
Free software (SL) is present in many areas of social life, overcoming economic barriers, political, philosophical and cultural exclusion. This article aims to highlight the importance of integrating free software in the context of the classroom, from the experience with a class of 2nd year of elementary school in Fortaleza. The potential use of the computer and free software Linux 3.0 Educational and applications contributed significantly to the change in quality of education, enabling the digital and social inclusion and multiple literacies of teachers and students. The results and conclusions of this paper motivate the researcher to continue investigating and producing other educational materials and tutorials for digital applications of free software. Thus, it seeks to contribute to the dissemination of educational possibilities of the operating system and therefore for continuing education of teachers.
\end{abstract}

KEYWORDS: Free software. Linux Education. School inclusion. Meaningful learning. Literacies.

\section{CONSIDERAÇÕES INICIAIS}

Na sociedade contemporânea as mudanças tecnológicas são quase instantâneas e, por isso, exigem do cidadão formação condizente com os desafios da modernidade. O domínio capitalista de softwares proprietários exclui pessoas de menor poder aquisitivo do acesso às Tecnologias da Informação e Comunicação (TIC), como, por exemplo, celulares, TV, computadores e internet. Felizmente, o software livre (SL) está presente em muitos espaços do convívio social, vencendo barreiras econômicas, políticas, culturais e filosóficas da exclusão. Nesse sentido, a 
divulgação de experiências exitosas com softwares livres é imprescindível para a democratização das tecnologias e do conhecimento. Segundo Campos (2006), o software livre pode ser usado, copiado, estudado, modificado e redistribuído sem restrições. Esse autor destaca as quatro liberdades básicas associadas ao SL:

- A liberdade de executar o programa, para qualquer propósito (liberdade $n^{\circ} 0$ )

- A liberdade de estudar como o programa funciona, e adaptá-lo para as suas necessidades (liberdade $\mathrm{n}^{\circ} 1$ ). Acesso ao código-fonte é um pré-requisito para esta liberdade.

- A liberdade de redistribuir cópias de modo que você possa ajudar ao seu próximo (liberdade $n^{\circ} 2$ ).

- A liberdade de aperfeiçoar o programa, e liberar os seus aperfeiçoamentos, de modo que toda a comunidade se beneficie (liberdade $\mathrm{n}^{\circ} 3$ ). Acesso ao código-fonte é um pré-requisito para esta liberdade (CAMPOS, 2006).

Sendo assim, o conceito de software livre nos remete ao conceito de liberdade, ampliando as perspectivas de inclusão digital e social de milhares de pessoas. Conforme Freitas (2005), em tempos de computador e de internet, o contexto sociocultural propõe ao aluno diferentes formas de leitura e escrita. No entanto, a escola parece ignorar essas práticas. Em contrapartida, enquanto escola, devemos assumir uma nova proposta educativa, visando garantir a todas as crianças e jovens o acesso às TIC e a uma educação de qualidade, tendo em vista a inserção de todos na sociedade da informação e do conhecimento. Nessa perspectiva, o presente artigo tem como objetivo destacar a importância da inserção do software livre no contexto de sala de aula, para a construção de uma sociedade justa e democrática, a partir de um relato de experiência no município de Fortaleza, em que o uso potencial do computador e dos aplicativos do software livre contribuiu de forma significativa para mudanças na qualidade da educação, possibilitando a inclusão digital e social e letramentos múltiplos de professores e alunos.

\section{SOFTWARE LIVRE NA EDUCAÇÃO: LIBERDADE E LETRAMENTOS MÚLTIPLOS}

Conforme o dicionário Michaelis (1998), liberdade é: "Estado de pessoa livre e isenta de restrição externa ou coação física ou moral.”, "Poder de exercer livremente a sua vontade”. Toda pessoa tem necessidade de ser livre e desenvolver suas potencialidades para investigar, questionar, pesquisar, aprender, produzir conhecimentos e tecnologias necessários para a melhoria da qualidade de vida. O aluno, para exercer sua liberdade no processo de construção do conhecimento, precisa de motivação. Essa motivação só será possível mediante o desenvolvimento de atividades lúdicas, interativas e prazerosas. Nesse sentido, é de grande relevância a proposição, para o aluno, de atividades escolares com essas características para que ele se interesse pelo processo de aprendizagem. O computador conectado à internet é uma excelente ferramenta para esse propósito, pois os alunos de todos os níveis de ensino se rendem às múltiplas possibilidades de entretenimento, descobertas, interações e aprendizagens que aquele oferece. Ademais, as TIC materializam no contexto social e escolar uma diversidade de suportes comunicativos e linguagens que requerem de professores e alunos a aquisição de novas competências e habilidades para continuar conectadas com o mundo. A interação dos alunos em atividades coletivas faz com que se sintam pertencentes a um grupo, fazendo surgir neles motivação para aprender. As motivações podem ser básicas, quando 
refletem as múltiplas necessidades de sobrevivência física e proteção; culturais ou comportamentais, quando voltadas à sobrevivência psíquica e social. A motivação para aprender se inclui na última categoria (KENSKI, 2003, p. 114).

Inserir o computador e o software livre na educação cria condições para que os alunos tenham motivação para aprender e para que construam um novo enredo para suas vidas. Em consonância com essa assertiva, as Orientações Curriculares Nacionais para o Ensino Médio (2008) destacam a importância de múltiplos letramentos para a construção da autonomia do aluno na pósmodernidade:

O que se defende, portanto, é a absoluta necessidade de se avocar e levar adiante o desafio de criar condições para que os alunos construam sua autonomia nas sociedades contemporâneas - tecnologicamente complexas e globalizadas - [...], abrir-se para os múltiplos letramentos, que, envolvendo uma enorme variação demídias, constroem-se de forma multissemiótica e híbrida - por exemplo, nos hipertextos na imprensa ou na internet, por vídeos e filmes, etc. (MEC, 2008, p. 29).

Para Soares (2005, p. 47), letramento é “estado ou condição de quem não apenas sabe ler e escrever, mas cultiva e exerce as práticas sociais que usam a escrita”. Os professores, ao usarem o software livre e seus aplicativos, adquirem habilidades tecnológicas simples e descobrem que esses conhecimentos não são restritos a um pequeno grupo de pessoas por serem criadores ou usuários de um software proprietário qualquer. Para além de realizarem pesquisas para o planejamento de suas aulas na internet, os professores criam seu correio eletrônico, tornam-se membros de listas de discussão e comunidades de aprendizagem, produzem conteúdo digital para suas aulas e buscam sua própria formação continuada. Os alunos, por sua vez, têm vislumbrado o acesso às ferramentas do computador e ao mundo conectado em rede. Eles sentem-se incluídos, digital e socialmente, à medida que, utilizam o computador para ler, escrever, produzir textos, resolver problemas, acessar a internet, ouvir música, ver vídeos, usar recursos multimídia, interagir em comunidades virtuais e pesquisar; enfim, aprender, efetivamente. O trabalho com o software livre na escola não se limita ao professor e ao aluno. A gestão escolar também apropria-se desse sistema para dinamização das atividades administrativas e pedagógicas.

\section{SOFTWARE LIVRE NO PROCESSO ENSINOAPRENDIZAGEM: AUTORIA E AUTONOMIA}

O mercado de produção de softwares, seguindo a lógica capitalista, oferece às escolas um número considerável de softwares pagos, caracterizados como educativos. Contudo, eles não são elaborados com critérios pedagógicos. De acordo com Oliveira, Costa e Moreira (2001), esses softwares são apresentados de forma pretensiosa como sendo construtivistas, mas, na realidade, não o são. Além de não terem cunho pedagógico, eles não coadunam com a realidade onde serão trabalhados, pois são construídos sem considerar as necessidades e dificuldades dos alunos.

À medida que os professores se apropriam do software livre e passam a usá-lo no processo de ensino/aprendizagem, descobrem suas múltiplas possibilidades de criação de atividades a serem trabalhadas pelo aluno no computador. Isso significa que, por sua diversidade de 
recursos, o computador não ficará limitado apenas às pesquisas acadêmicas e elaboração de atividades para a sala de aula. Dessa maneira, o professor exerce a autoria de recursos pedagógicos digitais. Essa prática autoral do professor contribui para a melhoria da sua autoestima e o motiva para continuar explorando as possibilidades pedagógicas do computador e do software livre em sua prática de ensino. Esses educadores refutam o discurso de pessoas que desconhecem o software livre e negam sua importância e funcionalidade no contexto escolar e social. Nessa perspectiva, o aluno, à medida que desenvolve suas atividades no computador e vai descobrindo a relevância do software livre, é incentivado pelo professor a construir sua aprendizagem por meio de atividades de produção, exercendo a autoria de forma autônoma.

Com o uso de software livre no contexto de sala de aula e exercício da autoria, professores e alunos adquirem letramentos múltiplos e autonomia necessários para a construção de aprendizagens significativas. Nesse contexto, a autonomia pode ser compreendida como capacidade de superar os desafios educacionais e buscar novas descobertas, formas de ensinar e aprender com a utilização do SL no processo ensino/aprendizagem. Em consonância com o conceito de Piaget (1998), para quem autonomia é autogoverno. Autonomia significa, de acordo com o dicionário Mini-Aurélio Século XXI (2001), "Faculdade de se governar por si mesmo". Para o construcionismo, a construção de aprendizagens significativas só é possível mediante a interação do aluno com o objeto do conhecimento, com o computador (PAPERT, 2008).

Com o software livre, o professor é desafiado a fazer uso de aplicativos, como: Writer (editor de texto), Calc (planilha eletrônica), Impress (apresentação de slides) — todos pertencentes à suíte de escritório LibreOffice ${ }^{\mathrm{i}}$ - KolourPaint (programa de desenho) ${ }^{\mathrm{ii}}$ e Tux Paint ${ }^{i i i}$. O resultado desse desafio é uma prática ativa e crítica com liberdade e autonomia para produção de conhecimentos e recursos pedagógicos digitais que podem ser explorados por outros professores.

Garantia de recursos materiais e humanos na escola por si só não garantem a qualidade do ensino. Formação continuada dos professores e vontade de fazer a diferença são fatores determinantes para, além de inovar, transformar a educação. Não basta equipar as escolas com as melhores tecnologias se não houver envolvimento e uso eficazes. Belloni (1999) e Valente (2005, p. 144) afirmam que a formação do professor perpassa três dimensões que são: a didática, a pedagógica e a tecnológica; sendo a última a utilização proficiente dos recursos, estratégias pedagógicas de uso desses recursos, avaliação e seleção de material técnico e pedagógico. Valente (2005) aponta a importância de um redimensionamento das necessidades dos educadores e alunos de forma planejada para a inserção do computador na prática pedagógica.

A formação do professor deve prover condições para que ele construa conhecimento sobre as técnicas computacionais, entenda por que e como integrar computador na sua prática pedagógica e seja capaz de superar barreiras de ordem administrativa e pedagógica. Essa prática possibilita a transição de um sistema fragmentado de ensino para uma abordagem integradora de conteúdo e voltada para a resolução de problemas específicos do interesse de cada aluno. Finalmente, deve-se criar condições para que o professor saiba recontextualizar o aprendizado e a experiência vividos durante a sua formação para a sua realidade de sala de aula, compatibilizando as necessidades de seus alunos e os objetivos pedagógicos que se dispõe a atingir (VALENTE, 2005, p. 27). 


\section{LINUX EDUCACIONAL 3.0 E SEUS APLICATIVOS NA ESCOLA}

Desde 2005, o município de Fortaleza optou pelo uso do software livre nas escolas, especialmente nos Laboratórios de Informática Educativa (LIE). Inicialmente, a rede optou pelo Kurumin; depois, Big Linux e, em 2010, a opção foi pelo Linux Educacional 3.0. Primeiro aconteceu a migração e, depois, a formação dos professores no Centro de Referência do professor (CRP). O Centro de Referência do Professor foi criado pela Prefeitura de Fortaleza em 2000. Essa instituição municipal é um espaço de inclusão digital e social que abriga 143 computadores ligados à internet, destinados à formação de professores em Informática Educativa, estendendo o uso das tecnologias aos alunos, servidores e à população de modo geral.

Inicialmente, muitas escolas não tinham internet ou tinham problemas de conexão. Então, nas capacitações, a solução era aprender a usar os recursos que a escola dispunha: computadores com o Linux e seus aplicativos. Os mestres aprenderam a usar as ferramentas do software livre, como trabalhá-las com os alunos e a criar as próprias atividades curriculares no formato digital para partilhá-las com seus pares. Partilhavam, sobretudo, experiências e conhecimentos. Os professores que se identificavam com o Calc exploravam-no e realizavam oficinas para outros professores. O mesmo ocorria em relação aos demais aplicativos. A formação acontece permanentemente e, atualmente, a maioria dos professores de Laboratórios de Informática sabe elaborar recursos educativos no Linux. Em 2010, embora quase todas as escolas já fossem conectadas à rede mundial de computadores, na qual pode-se encontrar muitos recursos digitais (videoaulas, documentários, objetos de aprendizagem e exercícios online), os professores continuam a exercer a autoria, a produzir conhecimentos e recursos digitais pedagógicos com o Linux Educacional 3.0. Esse sistema operacional pode ser "baixado" no site do Ministério da

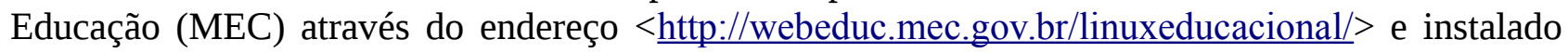
em qualquer computador.

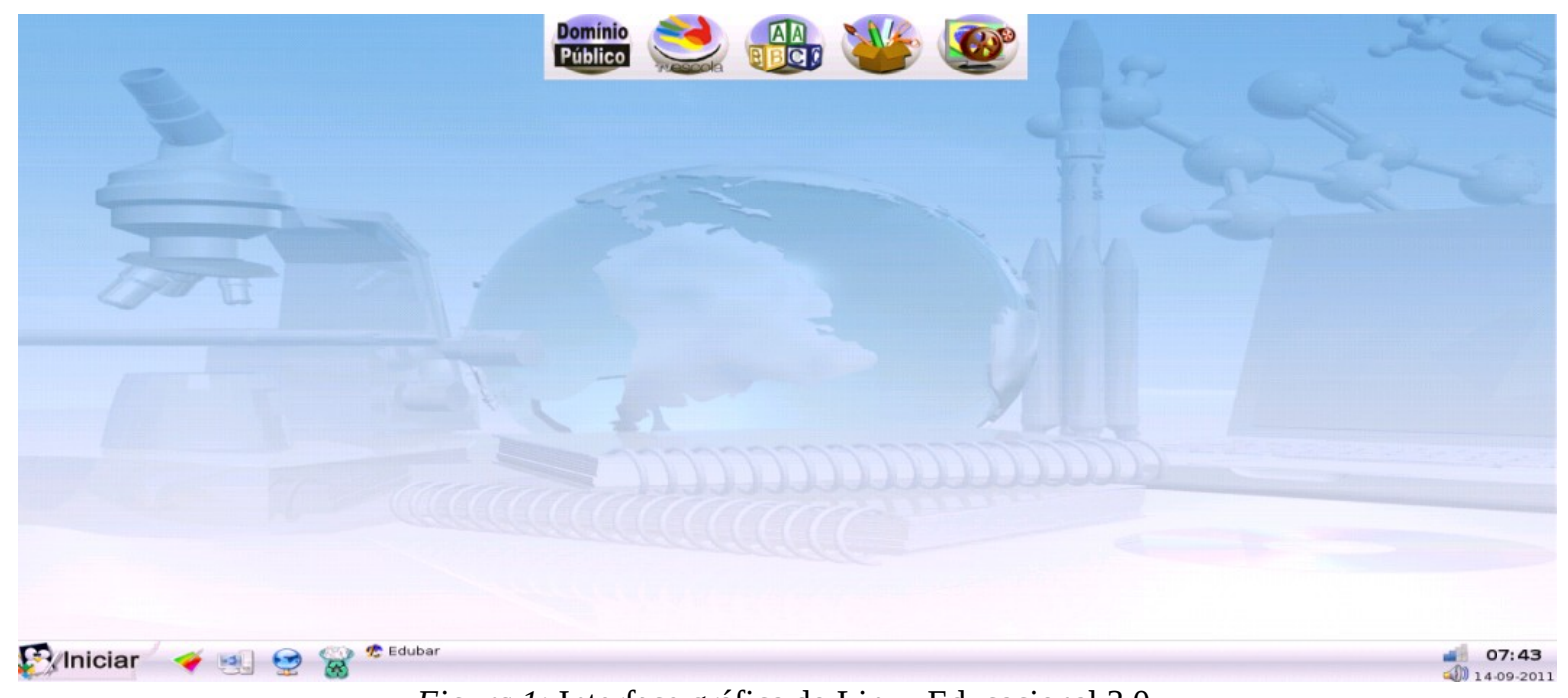

Figura 1: Interface gráfica do Linux Educacional 3.0.

Ao explorarmos os aplicativos Writer, Calc, Impress, KolourPaint e o softwareTux Paint, já citados, descobrimos neles infinitas possibilidades educativas que atendem as necessidades 
específicas de sala de aula. Para encontrar os aplicativos Writer, Calc e Impress no Linux Educacional, deve-se acessar o menu iniciar e, em seguida, ferramentas de produtividade. Para o KolourPaint, o caminho é o menu iniciar, gráficos e programa de pintura (KolourPaint). O Tux Paint, por sua vez, é encontrado clicando-se no menu iniciar, programas educacionais, multidisciplinar e programa de desenho (Tux Paint).

O editor de texto Writer oferece um leque de opções para a elaboração de atividades de leitura e interpretação, produção de textos, exercícios com palavras cruzadas, associações, questões com múltipla escolha, seleção e histórias em quadrinhos. O uso de recursos imagéticos, como gifs animados $^{\text {iv }}$, planos de fundo, fontes, cores e os recursos de desenhos do próprio editor deixam as atividades bem interessantes.

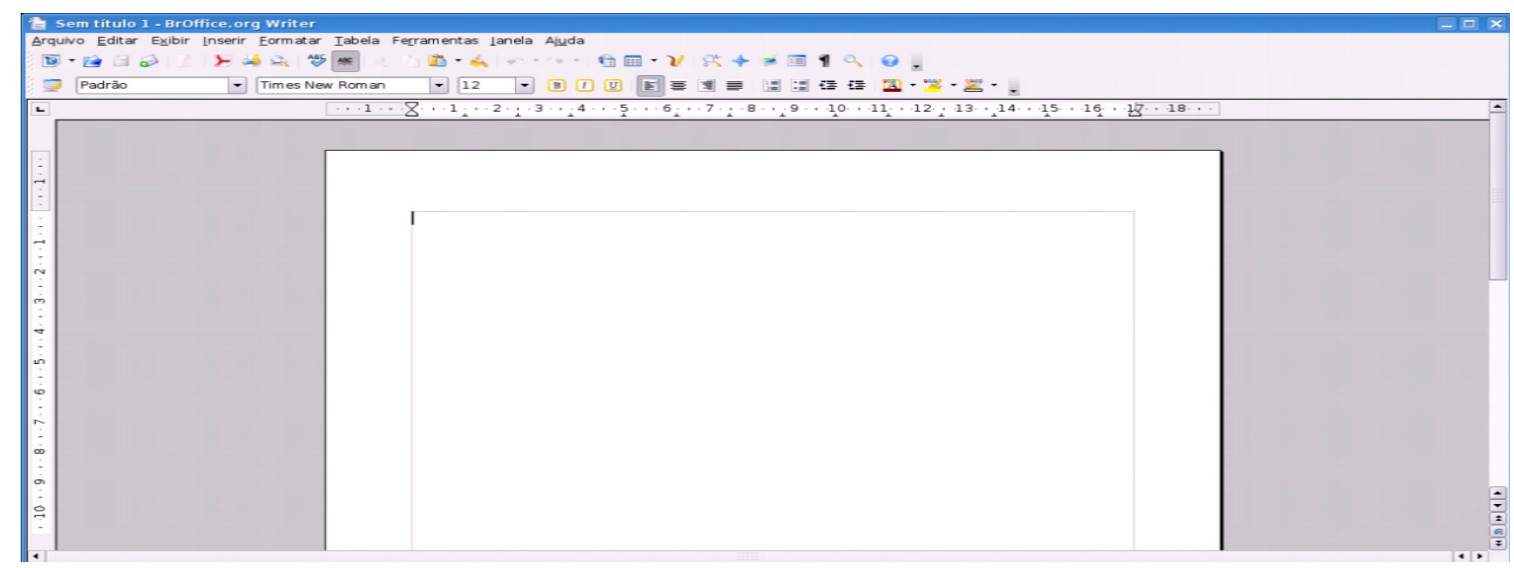

Figura 2: Interface gráfica do editor de textos Writer.
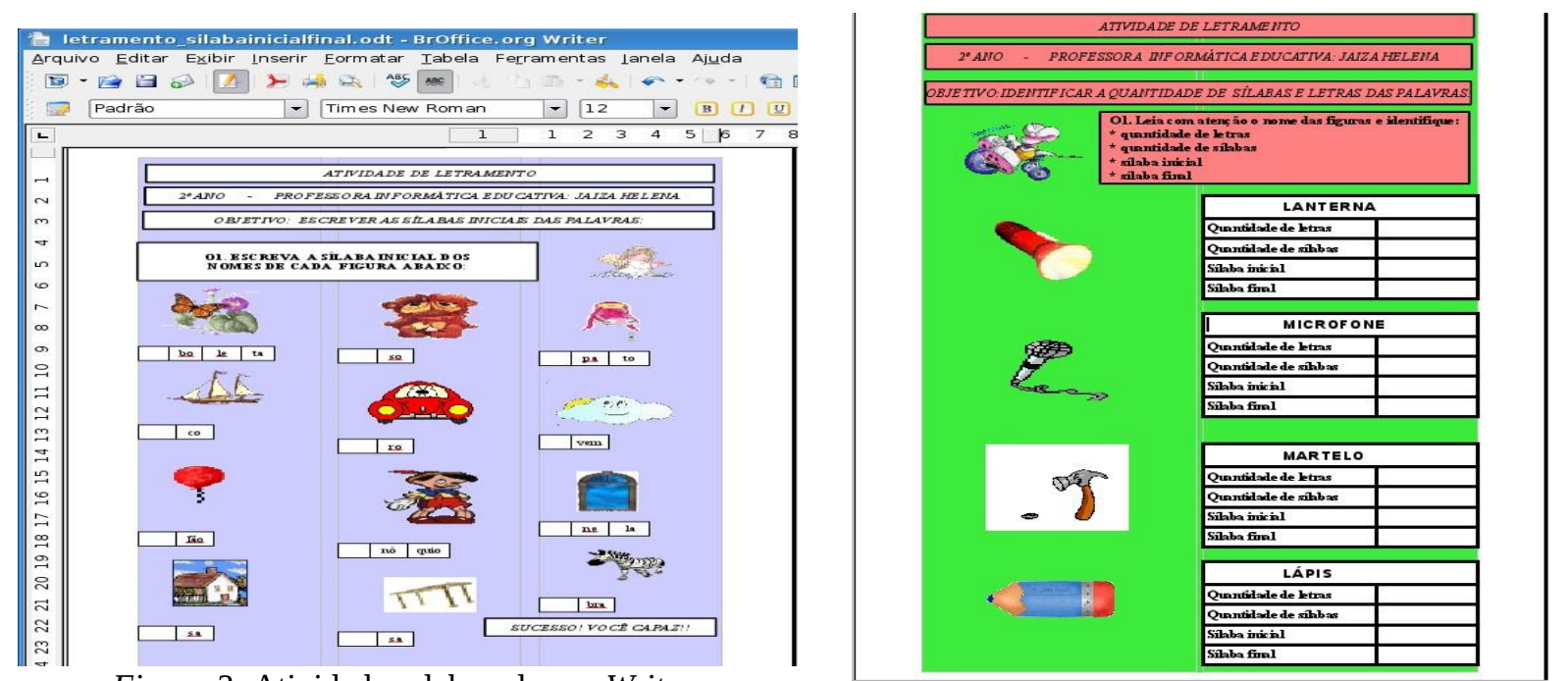

Figura 3: Atividades elaboradas no Writer.

A planilha eletrônica Calc, por sua vez, tem suas peculiaridades. Com ela, pode-se elaborar, a exemplo do Writer, atividades de leitura, interpretação e produção, palavras cruzadas, tabelas, gráficos e questões de associação. Além de dispormos dos recursos para formatação de fontes, imagens e cores, as atividades ficam bastante atraentes quando optamos pela formatação de 
estilos e condicionais. Quando o aluno acerta ou erra a resposta, há a indicação, por meio de uma cor específica da fonte, do fundo ou de uma determinada palavra ou expressão, como, por exemplo, para certo: "Parabéns"; para errado: “Tente novamente". A ludicidade da atividade vai depender da criatividade do professor.

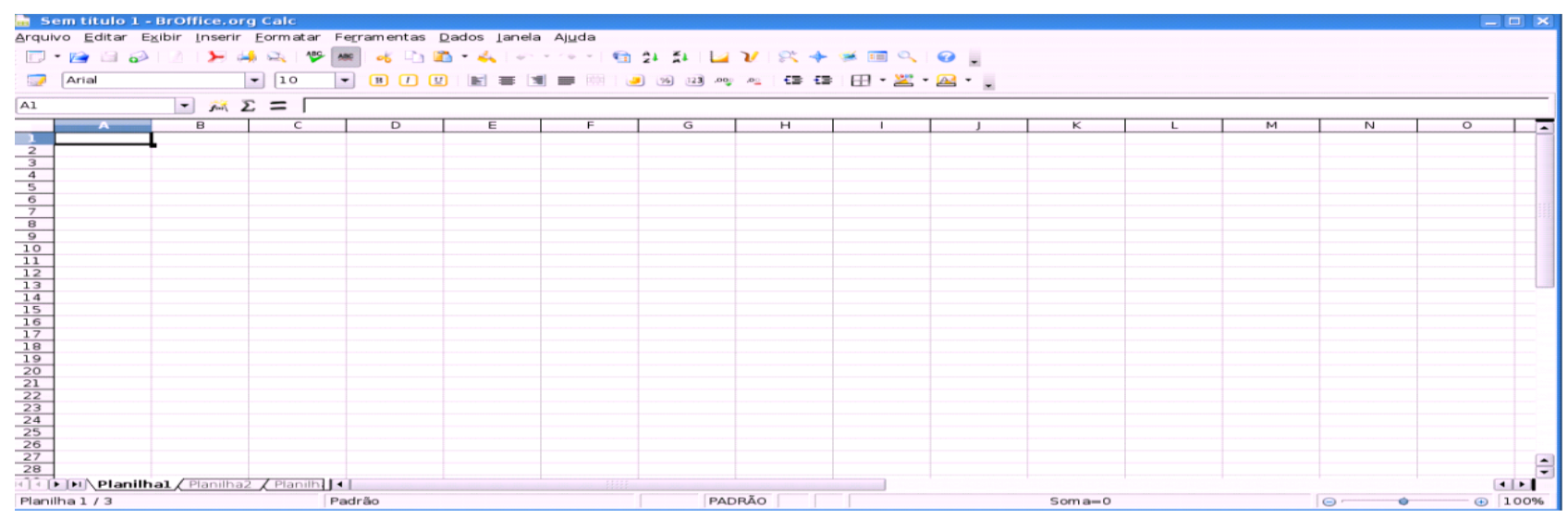

Figura 4: Interface gráfica da planilha eletrônica Calc.
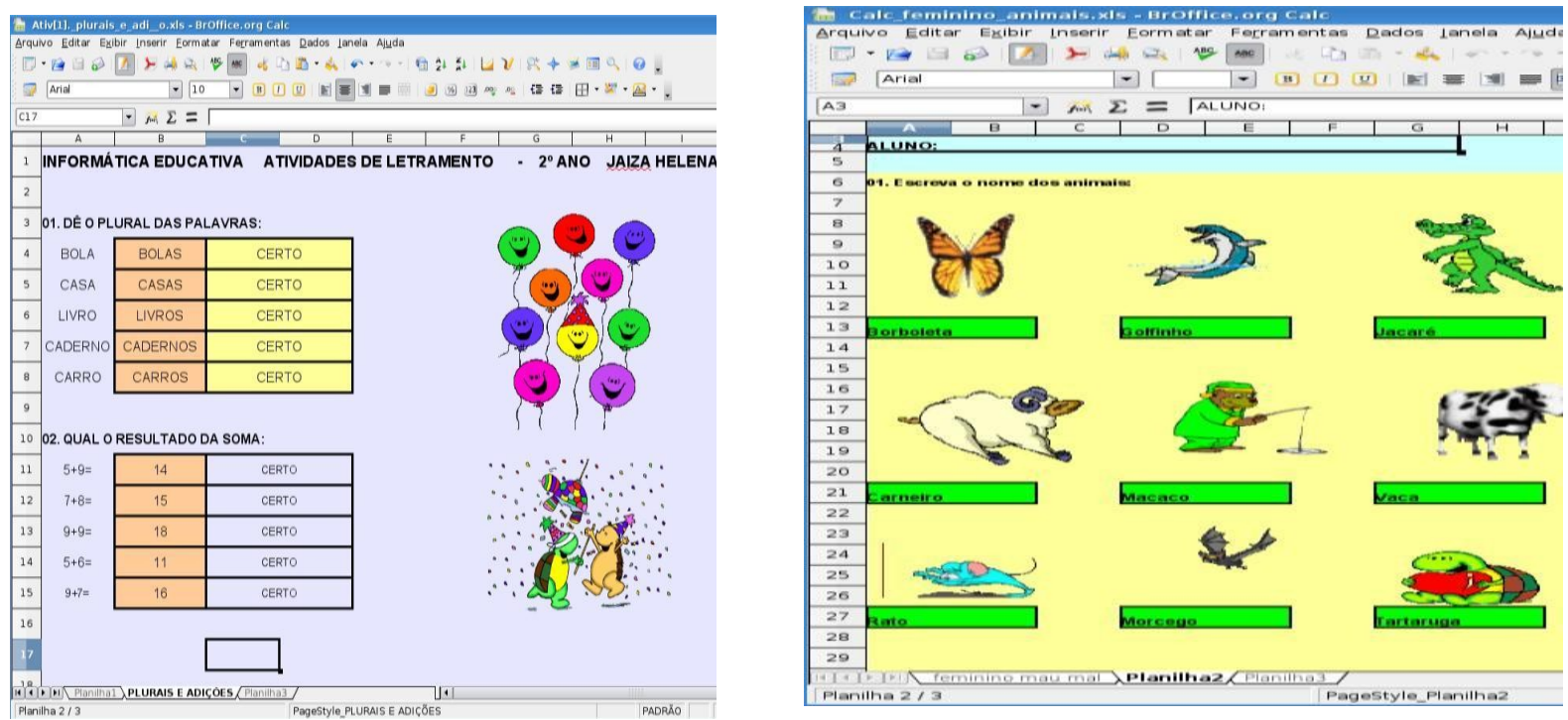

Figura 5: Atividades criadas no aplicativo Calc.

Para apresentação de slides, o Impress também tem se destacado muito como ferramenta de produção de material pedagógico. Esse aplicativo pode ser usado para apresentação de conteúdos curriculares. Os slides, para serem bem elaborados, devem conter recursos imagéticos e transição de slides diversificada. Uma boa opção é a transição aleatória. Pode-se criar atividades usando-se o recurso de links ${ }^{v}$ no próprio documento. Em uma questão de múltipla escolha, se o aluno acertar, o link pode remetê-lo a outro slide com "Parabéns!” ou "Você acertou!”, e, se errar, “Que pena!” ou “Tente novamente!”. Outra proposta é a digitalização de livros em que cada página é transformada em imagens com as quais se cria slides para serem lidos e explorados no computador pelo aluno. 


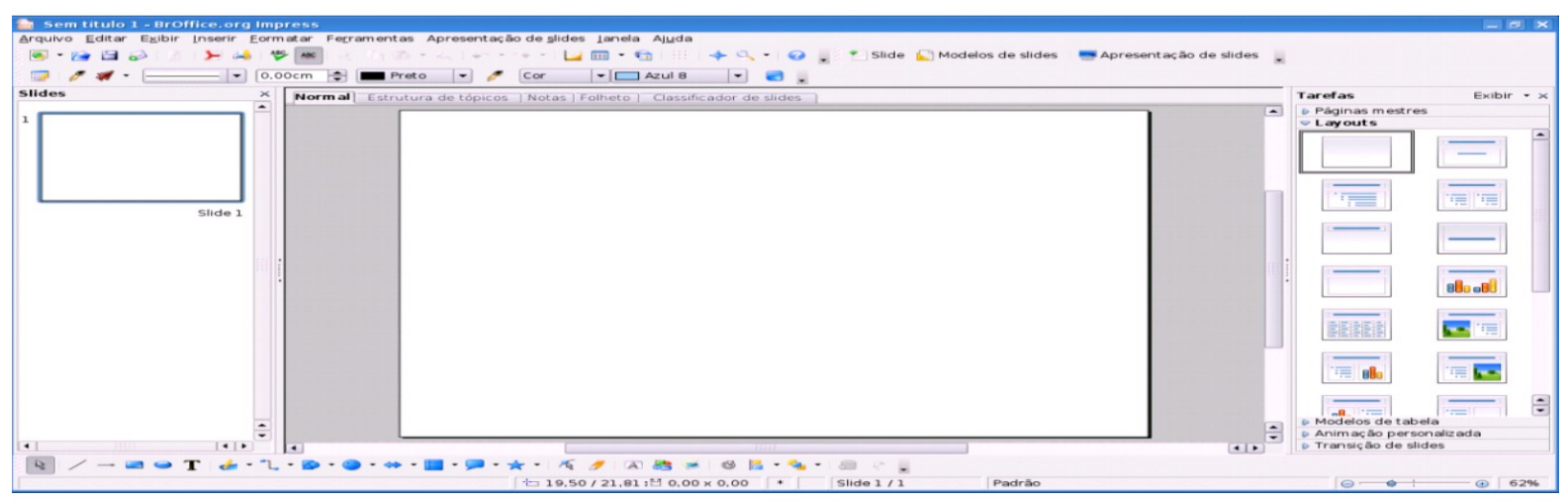

Figura 6: Interface gráfica do Impress.
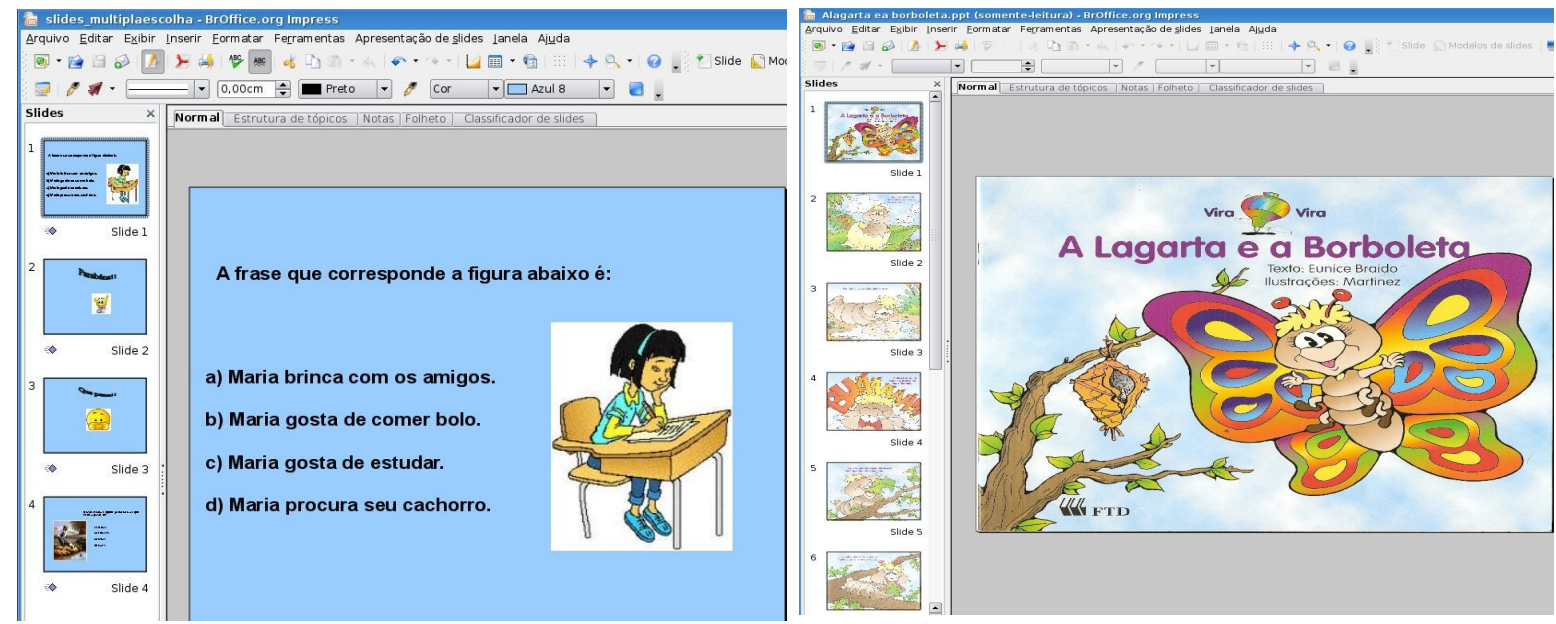

Figura 7: Atividades de leitura e interpretação de texto construídas no Impress.

O KolourPaint é um aplicativo de desenho e pintura que pode ser usado não apenas para explorar a criatividade artística do aluno, mas, sobretudo, para elaboração de atividades por parte do professor. Esse recurso possibilita a inserção de imagens com as quais o professor poderá solicitar que o aluno produza frases, textos, histórias em quadrinhos, ou que resolva desafios de sete erros, bem como, a exemplo dos outros aplicativos, questões de múltipla escolha.

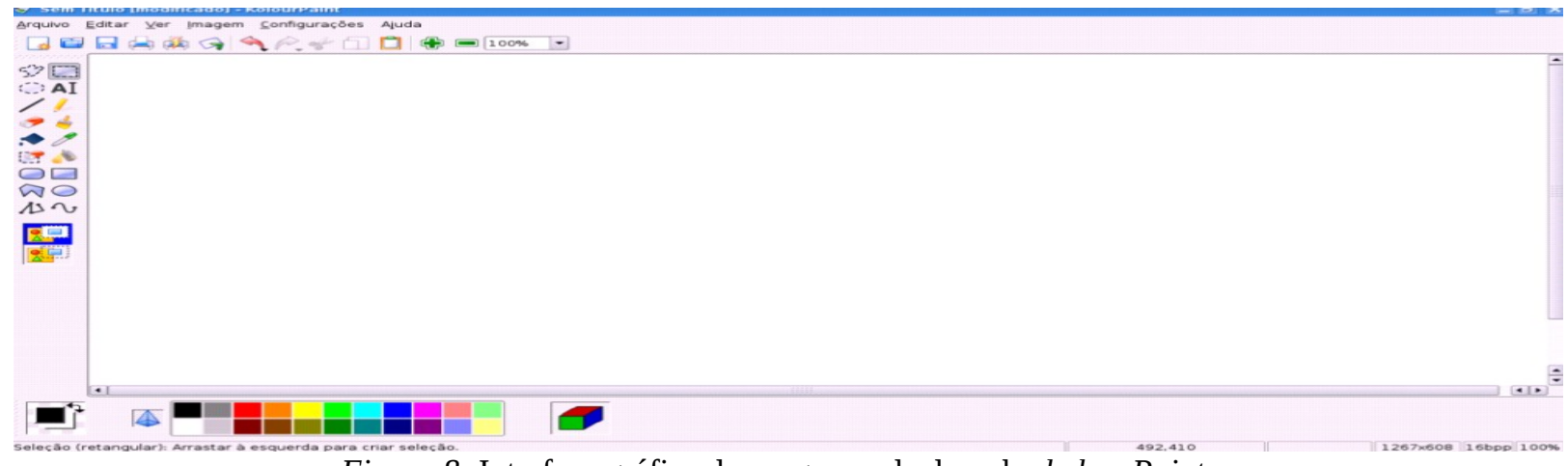

Figura 8: Interface gráfica do programa de desenho kolourPaint. 

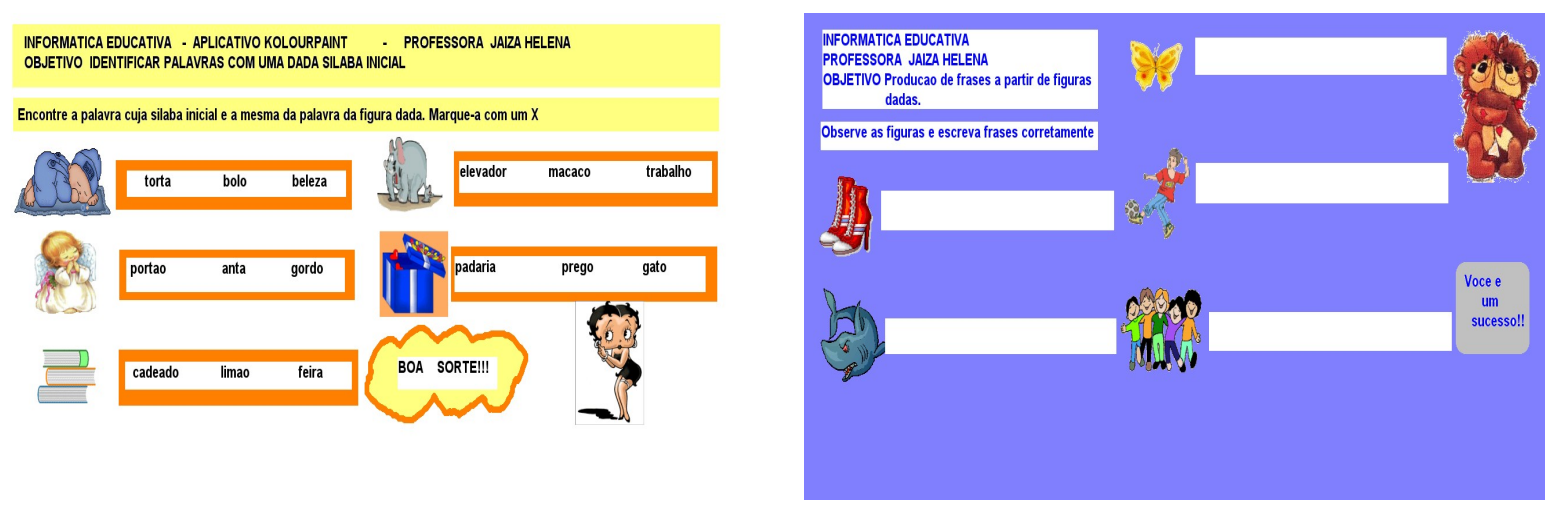

Figura 9: Exemplos de atividades elaboradas no KolourPaint.

Por fim, o Tux Paint, software livre infantil, que já vem instalado no Linux Educacional 3.0, é uma ferramenta bastante útil para o trabalho pedagógico na sala de aula devido ao grande número de recursos com os quais se pode criar uma infinidade de atividades curriculares. Vale ressaltar que apesar de ser um software infantil, ele pode ser utilizado na produção de material para qualquer série do Ensino Fundamental, haja vista a diversidade de ferramentas. Ele contém carimbos que podem ser inseridos na tela, como, por exemplo, planetas, alimentos, objetos, transportes, flores, formas geométricas (vazadas, cheias), mágicas (arcoíris, gramas, tijolos, clarear, escurecer) entre outros. Cada ferramenta que se encontra à esquerda disponibiliza vários recursos à direita. Ademais, pode-se personalizar as produções, inserindo-se fotos ou imagens de nosso interesse para serem trabalhadas no software. Ao abrir o Tux Paint, o professor já pode trabalhar com os alunos cores ou conceitos topológicos, como, alto, baixo, maior, menor, em cima, embaixo, perto, longe, largo, estreito, fino, grosso, à direita, à esquerda. No Tux Paint existem ferramentas para aumentar, diminuir, espelhar e virar as imagens. Desta feita, o professor pode solicitar que o aluno desenhe ou use os carimbos para colocar uma árvore e uma casa na tela; depois, à esquerda da casa, uma pessoa; no telhado, um gato maior e um menor e embaixo da árvore, uma galinha e um porco (Figura 12). As possibilidades educativas do software vão depender da criatividade do professor.

Ressalta-se a importância desse software para trabalhar a sensibilidade, a percepção e a criatividade artística dos alunos, uma vez que é um recurso ímpar para a criação de telas que sugerem leitura e produção escrita de histórias. É importante frisar que toda atividade elaborada no Tux Paint tem o formato de imagem, extensão .png. Desse modo, para que o aluno consiga realizar as atividades propostas, elas devem ser abertas e trabalhadas no aplicativo KolourPaint. O download do software pode ser feito no site <http://www.tuxpaint.org/>. Exemplos de produções com o uso do Tux pode ser encontrados no blog da professora Liduina, $<$ http://atividadesnotuxpaint.wordpress.com $/>$. 


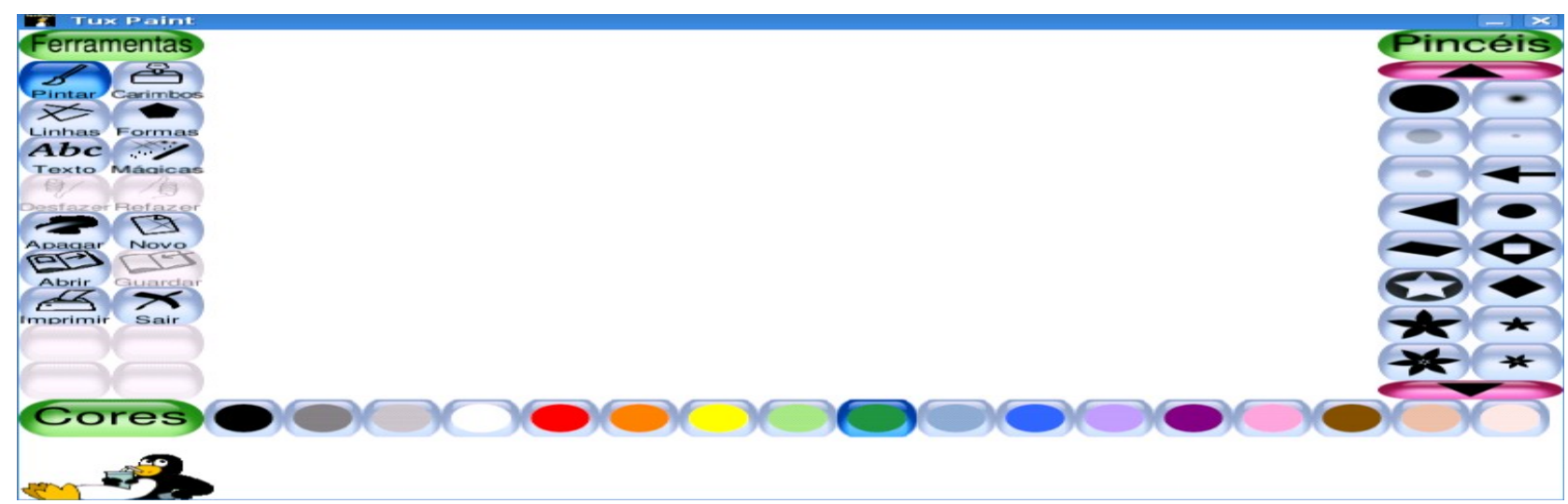

Figura 10: Interface gráfica do software Tux Paint.
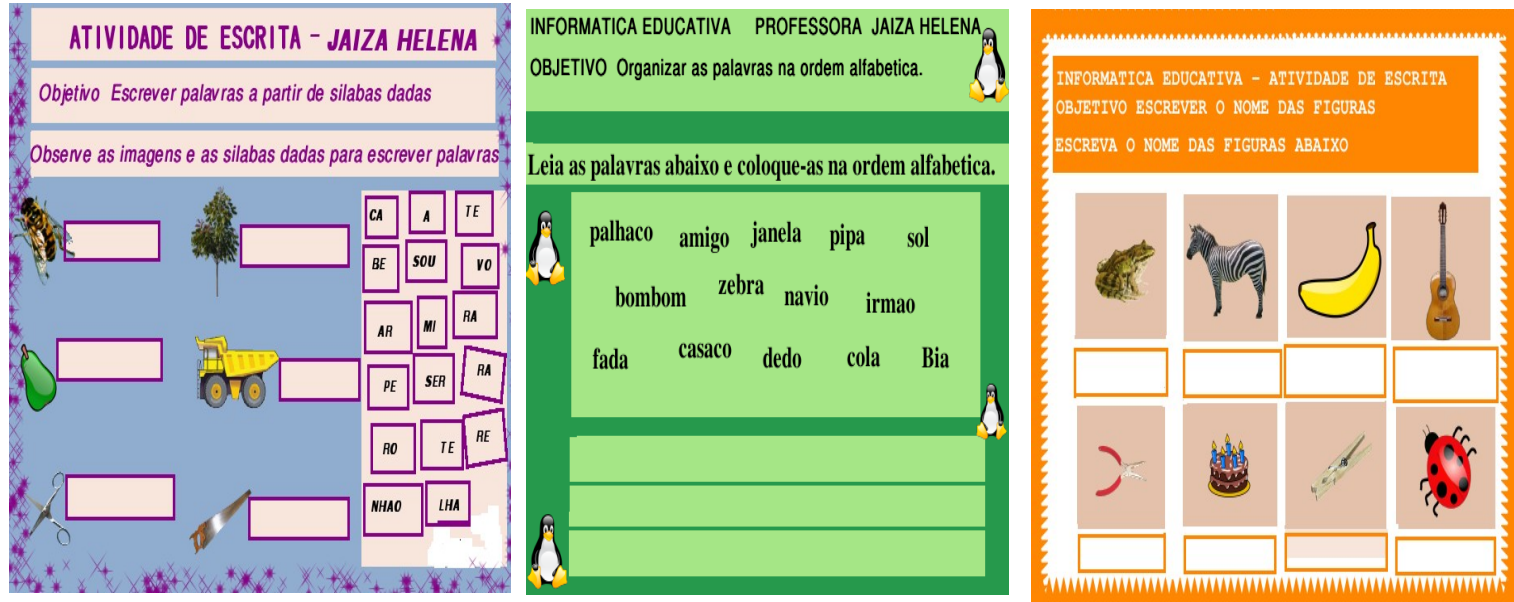

Figura 11: Exercícios elaborados no Tux Paint.

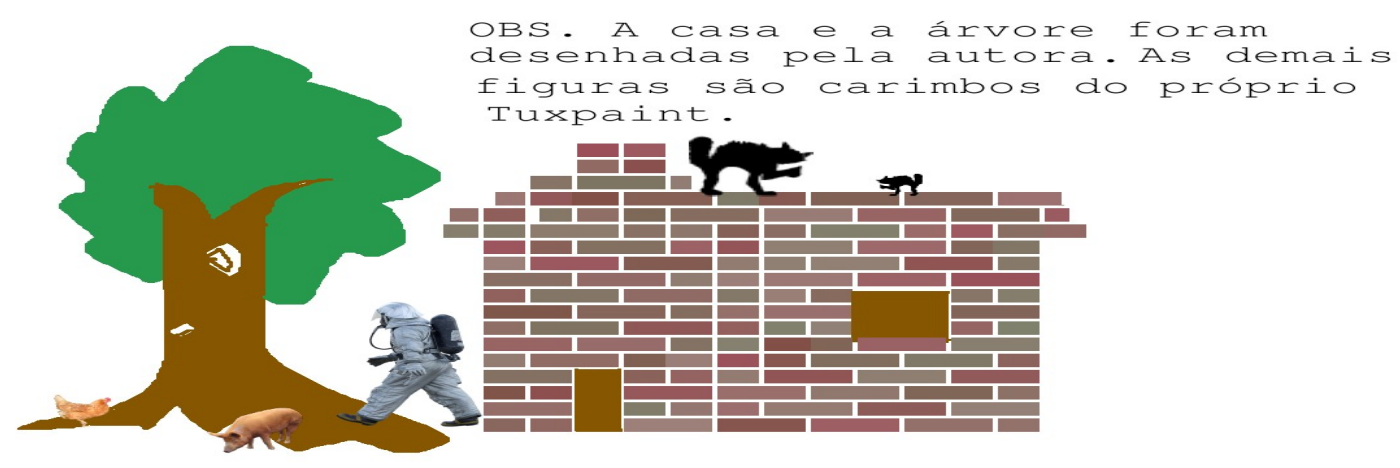

Figura 12: Exploração de conceitos topológicos.

A partir do que apresentamos acerca do uso potencial dos aplicativos do software livre 
para a criação de recursos digitais pedagógicos e facilitadores do processo de aprendizagem dos alunos de forma significativa, é imperativo destacar as características que são próprias de um software educativo de acordo com o pensamento de Oliveira (2001, p. 74):

- definição e presença de uma fundamentação pedagógica que permeie todo o seu desenvolvimento;

- finalidade didática, por levar o aluno/usuário a “construir” conhecimento relacionado com o seu currículo escolar;

- interação entre aluno usuário e programa, mediada pelo professor;

- facilidade de uso, uma vez que não se devem exigir do aluno conhecimentos computacionais prévios, mas permite que qualquer usuário, mesmo que em um primeiro contato com a máquina, seja capaz de desenvolver suas atividades;

- $\quad$ atualização quanto ao estado da arte.

A seguir, abordaremos uma experiência, que consideramos exitosa, de uso do software livre Linux Educacional 3.0 e seus aplicativos no contexto escolar. A professora do Laboratório de Informática Educativa produziu material pedagógico e o explorou com turmas de $2^{\circ}$ Ano do Ensino Fundamental I, visando não apenas a inclusão digital e social desses alunos, mas, sobretudo, letramentos múltiplos de todos os envolvidos no projeto, professores e alunos. Os resultados foram promissores, criando expectativas para trabalhos futuros com alunos de outras séries e níveis de ensino.

\section{O PROJETO “SOFTWARE LIVRE NA EDUCAÇÃO: PARA ALÉM DA INCLUSÃO DIGITAL E SOCIAL, O LETRAMENTO”}

Reflexões acerca dos resultados negativos na avaliação do Programa de Alfabetização na Idade Certa (PAIC) 2009 das turmas de $2^{\circ}$ Ano do Ensino Fundamental I de duas escolas públicas municipais de Fortaleza fez surgir, nesse contexto, a necessidade de intervenção com o uso do Linux Educacional 3.0. De acordo com o site do projeto, PAIC é o Programa de Alfabetização na Idade Certa lançado em 2007 pelo governo do Estado do Ceará, que, em parceria com os municípios do Estado, assumiram o compromisso de alfabetizar todas as crianças da rede pública até os sete anos de idade. O PAIC, portanto, passou a fazer parte do Sistema Permanente de Avaliação da Educação Básica do Ceará - SPAECE, realizado no Estado desde 1992 para avaliação do desempenho acadêmico dos alunos em Língua Portuguesa e Matemática. Até 2007 o foco do SPAECE eram turmas de $5^{\circ}$ e $9^{\circ}$ anos do Ensino Fundamental e $1^{\circ}$ ano do Ensino Médio. A partir de então, o foco foi ampliado para as turmas do $2^{\circ}$ Ano do Fundamental I, chamado "SPAECE - Alfa", e as demais turmas do Ensino Médio. Portanto, a avaliação do PAIC corresponde aos resultados obtidos no SPAECE - Alfa.

A partir das reflexões em torno das aprendizagens dos alunos dos $2^{\circ}$ Anos das escolas citadas, elaboramos e aplicamos, nessas turmas, entre Dezembro de 2010 e Janeiro de 2011, o projeto "Software livre na educação: para além da inclusão social e digital, o letramento". O projeto teve fundamentação teórica em Matos (2006), que defende o SL como potencializador da inclusão digital; no conceito de letramento de Soares (2005) e na proposta construcionista de Papert (2008) para o uso do computador na escola. A experiência foi realizada com o objetivo de analisar o 
potencial pedagógico do SL e seus aplicativos para melhoria das habilidades de leitura e escrita e o letramento dos alunos envolvidos no processo para o sucesso nas avaliações do PAIC 2010. Os objetivos específicos perseguidos foram: (i) elaborar atividades lúdicas com os aplicativos do SL Linux Educacional 3.0 - possibilitando ao professor o exercício da autoria - para alunos do $2^{\circ}$ Ano do Fundamental I; (ii) aplicar as atividades elaboradas nas turmas envolvidas com o projeto na Informática Educativa, visando a melhoria na aquisição da leitura e da escrita e do letramento desses alunos e, por fim, (iii) identificar as possibilidades educativas do software livre para o letramento dos envolvidos no projeto, professores e alunos.

Essa experiência investigativa de natureza qualitativa foi desenvolvida em seis turmas de $2^{\circ}$ Ano (três turmas em cada escola), nas quais esta autora atua como professora de Informática Educativa. A carga horária correspondeu a 02h/a semanais, totalizando 20h/a em cada turma. O público alvo era, aproximadamente, 150 alunos entre sete e oito anos de idade e seus respectivos professores, seis no total. Inicialmente, a professora do Laboratório de Informática Educativa fez a sondagem das necessidades de leitura e escrita das turmas e, através do exercício da autoria, elaborou atividades lúdicas diversas usando os aplicativos Writer, KolourPaint, Calc, Impress e o software Tux Paint. Em seguida, os alunos, acompanhados de seus professores de sala de aula, realizaram as atividades propostas de leitura e escrita no laboratório.

Por fim, a avaliação do projeto foi feita por meio de registros da observação do desempenho dos alunos no laboratório e através de entrevista focal com os alunos e seus respectivos professores para verificação do grau de satisfação de todos.

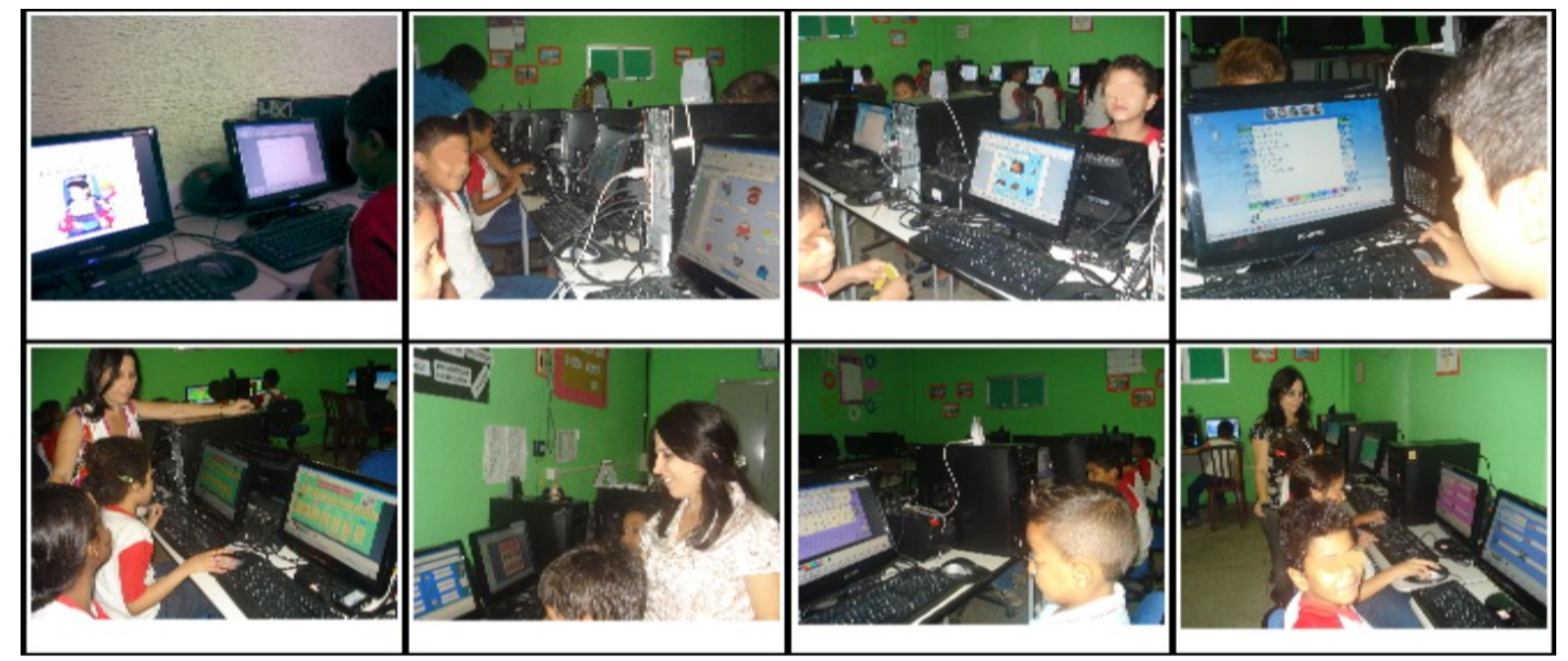

Figura 13: Imagens de aplicação do projeto.

\section{RESULTADOS}

Constatou-se melhoria na motivação dos alunos, visto que demonstravam muito interesse nas atividades propostas, empenhando-se para concluí-las com êxito. Seus relatos demonstraram que estavam felizes, pois aprenderam a ler e a escrever através do computador. Os professores, por seu turno, relataram que perceberam avanços na motivação e aprendizagem dos alunos. O sucesso do projeto foi observado também na melhoria das notas nas duas escolas no 
PAIC, pois passaram de 3,0 e 3,5, em 2009, para 6,11 e 5,17, respectivamente, em 2010. Esses resultados interferiram no Índice de Desenvolvimento da Educação Básica (IDEB) ${ }^{\text {vi }}$ das escolas e, por conseguinte, nos resultados da rede de ensino. As notas das duas escolas no IDEB, atualmente, é 4.3 e 4.6, superando as metas previstas para 2011. Enfatizamos, pois, a importância dessa experiência com o SL para o alcance dos resultados pretendidos como melhoria no processo de leitura e escrita dos alunos, identificação de várias possibilidades educativas do software livre para o exercício da autoria e construção de aprendizagens significativas por professores e alunos.

\section{CONSIDERAÇÕES FINAIS}

O uso do software livre e seus aplicativos, através de uma proposta de informática educativa, possibilita ao professor a criação e a aplicação de recursos pedagógicos digitais no processo de ensino e de aprendizagem. O software livre pode ser uma ferramenta de ensino ímpar para ser trabalhada em qualquer série do Ensino Fundamental. Cabe ao professor adaptar essa ferramenta livre às necessidades do processo processo educativo para a construção de aprendizagens significativas. O SL, portanto, contribui para a inclusão digital e social e letramentos múltiplos de professores e alunos.

Os resultados e conclusões deste artigo motivam a pesquisadora a continuar investigando e produzindo outros materiais pedagógicos digitais e tutoriais dos aplicativos do software livre. Dessa forma, buscamos contribuir para a divulgação das possibilidades educativas desse sistema operacional junto aos envolvidos no projeto e para a formação continuada de outros professores.

\section{REFERÊNCIAS BIBLIOGRÁFICAS}

BRASIL. Ministério da Educação e do Desporto. Orientações Curriculares para o Ensino Médio: linguagens, Códigos e suas Tecnologias. Secretaria de Educação Básica. Brasília: MEC/2008.

CAMPOS, Augusto. O que é software livre. BR-Linux. Florianópolis, março de 2006. Disponível

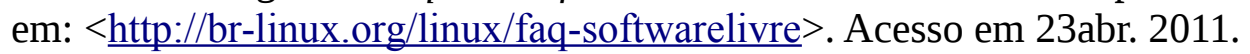

FERREIRA, A B. de H. Mini Dicionário Aurélio da Língua Portuguesa: século XXI. 5 a ed. Rio de Janeiro: Editora Nova Fronteira, 2001.

FREITAS, M. T. de A. Leitura, escrita e literatura em tempos de internet. In: PAIVA, Aparecida; ARACY, Martins; PAULINO, Graça; VERSIANI, Zélia (Orgs). Literatura e letramento: espaços, suportes $e$ interfaces - $o$ jogo do livro. 1. ed. 1 reimp. Belo Horizonte: Autêntica/CEALE/FaE/UFMG, 2005.

KENSKI, V. M. Tecnologias e ensino presencial e a distância. Campinas, SP: Papirus. 2003.

MATOS, Márcia de Melo. Egressos de Inclusão Digital: estudo avaliativo. Dissertação de mestrado. Fortaleza: UFC/FACED, 2006, 117P.

OLIVEIRA, C. C. de O.; COSTA, J. W.; MOREIRA, M. Ambientes Informatizados de Aprendizagem: produção e avaliação de software educativo. Campinas, SP: Papirus, 2001.

PAIVA, Aparecida; ARACY, Martins; PAULINO, Graça; VERSIANI, Zélia (Orgs). Literatura e 
letramento: espaços, suportes e interfaces - o jogo do livro - 1. ed. 1 reimp. Belo Horizonte: Autêntica/CEALE/FaE/UFMG, 2005.

PAPERT, Seymour. A máquina das crianças: repensando a escola na era da informática. ed. rev. Porto Alegre: Artmed, 2008.

PIAGET, J. Sobre a pedagogia. São Paulo: Casa do Psicólogo, 1998.

SOARES, Magda. Letramento: um tema em três gêneros. 2. ed. 10 reimpr. Belo Horizonte: autêntica, 2005.

SOARES, Magda. Alfabetização e letramento. $3^{\text {a }}$ Ed. São Paulo: Contexto, 2005.

VALENTE, J. A.; PRADO, M. E. B.; ALMEIDA, M. E. B. (Org.). Educação a distância via Internet. $2^{\mathrm{a}}$ Edição, São Paulo: Avercamp, 2005.

\section{ENDEREÇOS ELETRÔNICOS:}

CRP - Centro de Referência do professor. Pesquisado em 12/09/2011. Disponível em:

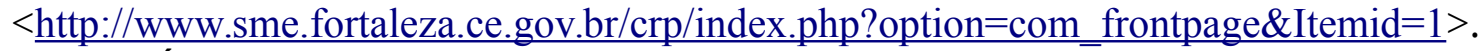

IDEB - Índice de desenvolvimento da Educação Básica. < $\underline{\text { http://portalideb.inep.gov.br/index.php? }}$ option $=$ com_content\&view $=$ article \&id $=45 \&$ Itemid $=5>$.

$<$ http://educarparacrescer.abril.com.br/nota-da-escola/ $>$.

DICIONÁRIO MICHAELLIS ONLINE. Moderno Dicionário da Língua Portuguesa. São Paulo: Editora Melhoramentos Ltda, $1998 . \quad$ Disponível em:

$<$ http://michaelis.uol.com.br/moderno/portugues/index.php?lingua=portuguesportugues\&palavra=liberdade pesquisado em 22/04/2011>.

PAIC - $\quad$ Programa de Alfabetização na Idade Certa.

$<$ http://www.idadecerta.seduc.ce.gov.br/index.php/apresentacao $>$.

SPAECE - Sistema de Avaliação da Educação Básica do Ceará.

$<$ http://www.spaece.caedufjf.net/spaece-inst/inicio.faces $>$.

LINUX EDUCACIONAL 3. 0 - http://webeduc.mec.gov.br/linuxeducacional

SITE OFICIAL DO TUX PAINT: < $\underline{\text { http://www.tuxpaint.org/>. }}$

BLOG COM ATIVIDADES ELABORADAS NO TUX PAINT:

$<$ http://atividadesnotuxpaint.wordpress.com/ $>$. 
i Site oficial: $<$ http://pt-br.libreoffice.org/ $>$.

ii Site oficial: $<$ http://www.kolourpaint.org/>.

iii Site oficial: $<\underline{\text { http://tuxpaint.org }>>\text {. }}$

iv Um GIF animado é o termo dado às animações formadas por várias imagens GIF compactadas numa só. É utilizado para compactar objetos em jogos eletrônicos para usar como emotion em mensageiros instantâneos e para enfeitar sites na Internet. (Disponível em: $<$ http://pt.wikipedia.org/wiki/Graphics_Interchange_Format $>$. Acesso em: 25 set. 2011).

v A palavra inglesa link entrou na língua portuguesa por via de redes de computadores (em especial a Internet), servindo de forma curta para designar as hiperligações do hipertexto. O seu significado é "atalho", "caminho" ou "ligação". Através dos links é possível produzir documentos não lineares interconectados com outros documentos ou arquivos a partir de palavras, imagens ou outros objetos. (Disponível em: $<$ http://pt.wikipedia.org/wiki/Hiperliga \% $3 \% \mathrm{~A} 7 \% \mathrm{C} 3 \% \mathrm{~A} 3 \mathrm{o}>$. Acesso em: 25 set. 2011).

vi O Î́ndice de Desenvolvimento da Educação Básica (Ideb) foi criado pelo Inep em 2007 e representa a iniciativa pioneira de reunir num só indicador dois conceitos igualmente importantes para a qualidade da educação: fluxo escolar e médias de desempenho nas avaliações. O indicador é calculado a partir dos dados sobre aprovação escolar, obtidos no Censo Escolar, e médias de desempenho nas avaliações do Inep,o Saeb - para as unidades da federação e

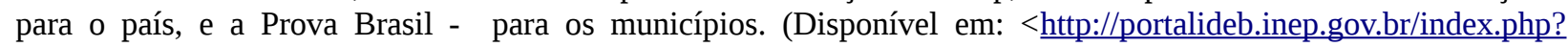
option=com content\&view=article\&id=45\&Itemid=5>. Acesso em: 25 set. 2011). 